\title{
Relação entre a leitura de livros e o desempenho acadêmico: análise com discentes de ciências sociais aplicadas
}

\author{
Camila Paniz Mallmann \\ https://orcid.org/0000-0001-5275-0127 \\ Vitor Hideo Nasu \\ https://orcid.org/0000-0001-5275-0127
}

Maria José Carvalho de Souza Domingues

https://orcid.org/0000-0001-7771-144X

\section{Resumo}

Objetivo: Investigar, de forma geral e comparativa, a relação entre a leitura de livros extracurriculares e o desempenho de discentes da área de ciências sociais aplicadas.

Método: Coletaram-se microdados de 338.977 alunos de nove cursos de graduação do Exame Nacional de Desempenho de Estudantes (Enade) de 2018. O desempenho no Enade é medido pelas notas nas provas de componente específico e de formação geral. Os dados foram analisados por meio de estatística descritiva, testes qui-quadrados e modelos de regressão.

Resultados: $\mathrm{O}$ curso de graduação está associado à leitura de livros extracurriculares. Em adição, há relação positiva entre a quantidade de livros lida e o desempenho acadêmico. Isso é válido para o desempenho nas provas de componente específico, de formação geral e, consequentemente, para o desempenho geral do discente no Enade 2018.

Contribuições: Recomenda-se que estudantes de graduação façam leituras além daquelas que constam nos programas das disciplinas, uma vez que os achados sugerem que a leitura de livros extracurriculares é relevante para a sua formação geral e específica e que, além disso, pode aprimorar as habilidades de leitura, interpretação de texto e escrita, aspectos fundamentais para se obter o resultado almejado nos cursos de graduação.

Palavras-chave: Livro; Leitura; Desempenho acadêmico; Ensino superior; Ciências sociais aplicadas. 


\section{Introdução}

O desempenho acadêmico dos estudantes no ensino superior tem sido apontado como um fator essencial para a formação e o desenvolvimento de um mercado de trabalho qualificado e competitivo. Organizações internacionais, como a Organização para a Cooperação e Desenvolvimento Econômico e o University Ranking by Academic Performance (2020), têm adotado o desempenho acadêmico dos alunos como base para analisar a qualidade do ensino superior dos países e elaborar estratégias e planos de ação para o desenvolvimento econômico e a redução da desigualdade social (Takala, Kallo, Kauko, \& Rinne, 2018).

Estudos têm analisado diversos fatores que podem influenciar o desempenho acadêmico, como variáveis relacionadas às Instituições de Ensino Superior (IES), ao corpo docente e ao corpo discente (Corbucci, 2007; Glewwe, Hanushek, Humpage, \& Ravina, 2015; Miranda, Lemos, Oliveira, \& Ferreira, 2015). Oliveira e Caggy (2013), por exemplo, constataram que a origem familiar e as condições financeiras e físicas podem influenciar relevantemente o desempenho discente.

As atividades extracurriculares também têm mostrado efeito favorável em relação à formação e ao comportamento social dos indivíduos (Bartkus, Nemelka, Nemelka, \& Gardner, 2012; Sauerwein, Theis, \& Fischer, 2016). Uma dessas atividades é a leitura extracurricular, que é a leitura realizada por vontade própria, por prazer, interesse, hobby ou outras motivações, que difere da leitura das referências bibliográficas básica e complementar das disciplinas (Nasu, 2018). A leitura extracurricular no ensino de línguas estrangeiras apresenta resultados positivos no desempenho das habilidades do estudante, aumentando o seu conhecimento cultural e a sua capacidade na interpretação de informações (Kuimova \& Ukhov, 2016).

O hábito de leitura dos estudantes pode contribuir de forma positiva para o desenvolvimento de competências, como planejamento, controle, gestão, contabilidade, finanças, comunicação e escuta (Cardoso, 2006). Quanto às competências profissionais, o hábito de leitura está interligado a funções de aprendizagem e utilidade que se aperfeiçoa à medida que se busca por leituras específicas (Nascimento, Garcia, \& Albuquerque Filho, 2019).

Embora estudos anteriores tenham contribuído com achados valiosos sobre os fatores determinantes do desempenho discente, ainda é incipiente a investigação sobre os efeitos da leitura extracurricular sobre a performance dos discentes da área de ciências sociais aplicadas, principalmente no que tange a estudos comparativos. Com base neste cenário, o objetivo desta pesquisa é investigar, comparativamente e de forma geral, a relação entre a leitura de livros extracurriculares e o desempenho acadêmico dos estudantes de cursos da área de ciências sociais aplicadas.

O estudo apresenta três justificativas para a sua consecução. Em primeiro lugar, a pesquisa trata de um tópico relevante para o desenvolvimento acadêmico e profissional de estudantes de graduação e que possui implicações para além do âmbito acadêmico. A análise da relação entre a leitura de livros extracurriculares e o desempenho discente pode servir de alerta a educadores, pais e aos próprios estudantes para que tomem medidas e ações que encorajem mais a leitura de variados assuntos. Pesquisamse, particularmente, os livros porque representam uma das fontes mais conhecidas e acessíveis para a realização de leitura.

Em segundo lugar, escolas e universidades podem elaborar projetos para promover atividades extracurriculares, dentre elas a atividade de leitura, já que têm o potencial de complementar a formação discente. Desta forma, a investigação da leitura de livros extracurriculares pode motivar o desenvolvimento de planos por parte de instituições educacionais (ex.: projetos de extensão e serviços à comunidade) a fim de aprimorar a qualidade do ensino e, consequentemente, a formação de seus estudantes.

E, em terceiro lugar, a análise comparativa permite que os cursos e seus coordenadores tenham noção de quão inclinados os seus estudantes estão para a prática de leitura em relação a estudantes de outros cursos universitários. Tal comparação pode servir de subsídio para coordenadores e professores tomarem decisões sobre formas de incentivar mais a leitura entre seus discentes, especialmente utilizandose de outros cursos como benchmarking. 
Em relação à estrutura do artigo, a seção 2 apresenta a revisão de literatura que serviu de apoio para esse estudo. Na seção 3, constam os aspectos metodológicos, incluindo a descrição da população e procedimentos para a formação da amostra, bem como o detalhamento das variáveis do estudo. Na seção 4, são reportados os resultados e a sua análise. Por fim, na seção 5 , são fornecidas a conclusão, limitações e sugestões para estudos futuros.

\section{Revisão da Literatura}

\subsection{A importância da leitura na formação e aprendizagem do indivíduo}

A leitura é necessária para o desenvolvimento pessoal e profissional, principalmente frente a mudanças (Kirsch \& Guthrie, 1984). Ela também possibilita a aprendizagem e o desenvolvimento de relações sociais em um processo que envolve aspectos como capacidade sensorial, motivação, percepção, pensamento e memória (Cantalice \& Oliveira, 2009). O desinteresse pela leitura, no entanto, é perigoso por ter implicações negativas para a sociedade. Por exemplo, um déficit na compreensão de textos e baixos rendimentos acadêmicos. Esse desinteresse pela leitura pode ser observado em alunos universitários, os quais, frequentemente, só leem aquilo que lhes é demandado pelos professores (Tourinho, 2011).

A leitura é o processo cognitivo de interpretar a fala que é escrita (Mol \& Bus, 2011). Ela proporciona ao leitor uma nova opinião sobre o tema lido. Desta forma, uma criança motivada a ler desde cedo está mais propensa a se tornar um adulto questionador e crítico; do contrário, não conseguirá facilmente formar opiniões sobre vastos assuntos devido à falta de base literária e de experiências (Arana \& Klebis, 2015).

Oliveira e Santos (2005) destacam a colocação de Garrido (1988) que indica que, em uma educação de qualidade, é evidente a relevância da leitura, ainda mais quando diversos discentes concluem o ensino fundamental e médio sem a mínima capacidade de ler e interpretar textos, e estes - ao iniciarem o ensino superior - se deparam com limitações e deficiências quanto ao comportamento de leitura. Similarmente, a habilidade de leitura é primordial para o estudante universitário, visto que o seu sucesso está relacionado à sua maturidade de ler (Oliveira \& Santos, 2005). O ato de ler expressa um grande passo para o indivíduo que busca por conhecimento, gerando capacidade de reflexão e questionamento sobre diversos fatos presentes no cotidiano (Oliveira, Santos, \& Primi, 2003).

Para alunos universitários, a leitura é substancial para a apreensão do conteúdo das disciplinas e da produção científica. Enquanto leitor competente, o estudante busca compreender as informações dos textos de forma crítica tanto na sua atuação acadêmica como profissional (Nascimento et al., 2019). Os universitários devem possuir uma leitura crítica de forma que tenham capacidade para discernir as informações contidas no texto e expor as opiniões do autor de forma adequada ao contexto da leitura (Hussein, 1999).

Espera-se que o discente apresente um nível de leitura satisfatório para compreender e analisar as informações do texto (Cantalice \& Oliveira, 2009). No entanto, pesquisas evidenciam que os estudantes universitários apresentam baixo nível de compreensão de leitura e indicam que isto pode interferir diretamente no desempenho acadêmico (Araújo, Camargos, Camargos, \& Dias, 2013; Oliveira \& Santos, 2006, 2005). As dificuldades são evidentes logo no início do curso e refletem no desempenho dos estudantes que ingressam na universidade (Silva \& Santos, 2004). 
As principais características dos leitores que possuem baixos níveis de compreensão de leitura são falhas no processo de decodificação do texto, ausência de vocabulário, deficiências na integração das informações, falhas na memorização, falta de estratégia de aprendizagem e falta de motivação pela leitura (Santos, Suehiro, \& Oliveira, 2004). Essas deficiências são, ao menos em parte, ocasionadas pela falta da prática de ler. Conforme os achados de Mokhtari, Reichard e Gardner (2009), o tempo gasto assistindo à televisão interfere no tempo destinado à leitura, além de os participantes terem declarado que dedicam a maior parte do seu tempo a atividades que envolvem conexão com a internet (ex.: e-mail, chat, redes sociais etc.). É razoável presumir que os alunos devotem mais tempo, hoje, a atividades no ambiente virtual, uma vez que há maior popularização do acesso à internet, o que sugere uma redução ainda mais acentuada do tempo dedicado à leitura. Além disso, Lieurya, Lorantb, Trosseillec, Champaultc e Vourc'hc (2014) encontraram relação positiva entre a leitura e o desempenho discente, em comparação ao uso de vídeo games.

A leitura é considerada a principal forma de obtenção de informações e está significativamente relacionada ao rendimento escolar (Nasu, 2018; Oliveira \& Santos, 2006, 2005; Silva \& Santos, 2004); afinal, o leitor rápido e preciso consegue adentrar o mundo dos conteúdos acadêmicos com maior facilidade (Oliveira \& Santos, 2005). Os problemas relativos à leitura e à produção de texto parecem ser os mais preocupantes aos olhos dos professores logo nos primeiros anos do ingresso de estudantes nas universidades (Sampaio \& Santos, 2002). Pesquisas apontam que deficiências na compreensão e a falta de leitura pelos universitários são responsáveis pela sua baixa performance, visto que a universidade demanda uma quantidade considerável de trabalho intelectual, exigido principalmente pela compreensão de textos (Marini, 1986). Desta forma, entender melhor como a leitura está associada ao desempenho discente é fundamental.

\subsection{Leitura extracurricular e estudantes da área de ciências sociais aplicadas}

De forma geral, atividades extracurriculares têm sido consideradas cruciais para alunos de negócios (Bartkus et al., 2012). Discentes que participam de tais atividades possuem habilidades interpessoais mais elevadas (Rubin, Bommer, \& Baldwin, 2002). Rynes, Trank, Lawson e Ilies (2003) constataram que a participação em atividades extracurriculares é uma maneira eficaz de introduzir aspectos de liderança nos estudantes da área de negócios, além de desenvolver a sua competência interpessoal. Uma dessas ativida des é a leitura que, embora seja essencial a todos os estudantes, foca-se, aqui, o debate sobre a sua relevância para aqueles da área de ciências sociais aplicadas.

A leitura extracurricular tem potencial para ajudar a melhorar a aprendizagem de maneira geral. Por exemplo, Silva e Santos (2004) avaliaram a compreensão em leitura por meio do teste de Cloze de 782 alunos de oito cursos de graduação (medicina, odontologia, administração, pedagogia, psicologia, letras, engenharia civil e matemática). Conforme os resultados, estudantes de administração obtiveram o terceiro pior desempenho de compreensão em leitura, superando apenas os colegas de odontologia e de engenharia civil. No estudo de Nascimento et al. (2019), foi verificado que os discentes de ciências contábeis apresentaram dificuldades em compreender o texto aplicado. A leitura de livros e outros materiais extracurriculares pode ajudar a melhorar a formação multidisciplinar do contador. Visões contemporâneas, como a Environment, Social e Governance (ESG), nem sempre são abordadas dentro do currículo de contabilidade. Por isso, a leitura sobre meio ambiente, diversidade social e outras temáticas extracurriculares pode ajudar os contadores na ampliação do seu conhecimento e na elaboração do relatório da administração e das demonstrações financeiras junto à administração da empresa, por exemplo. 
Tourinho (2011) argumenta que a prática da leitura é fundamental para a criação de cidadãos críticos que possam transformar a realidade a sua volta. A leitura afeta positivamente até a saúde mental, conforme constatou estudo com alunos universitários (Levine, Cherrier, Holding \& Koestner, 2020). Adicionalmente, os achados de McGaha e Fitzpatrick (2010) sustentam que quanto mais os estudantes leem, maior são as suas aspirações profissionais. Se tais estudantes usam mais livros e frequentam mais bibliotecas, é natural estarem mais envolvidos com o curso de graduação e terem aspirações profissionais mais fortes (McGaha \& Fitzpatrick, 2010). Cursos da área de ciências sociais aplicadas geralmente oportunizam crescimento de carreira significativo e, se os seus estudantes não souberem aproveitá-lo - em particular por falta de aspiração -, podem ficar estagnados profissionalmente. Nesse sentido, a leitura extracurricular, conforme sustentam os achados de McGaha e Fitzpatrick (2010), pode ajudar a inspirar os discentes profissionalmente, levando-os, ultimamente, a alcançar os patamares mais elevados de suas respectivas profissões.

Em termos de desempenho acadêmico, estudantes que não têm o hábito de ler regularmente estão mais propensos a obter performances mais baixas (Cunha \& Santos, 2006). Em uma análise com estudantes de administração, direito e psicologia, Oliveira e Santos (2006) observaram que há relação positiva entre a compreensão em leitura e o desempenho acadêmico, inclusive considerando a performance em disciplinas como comunicação empresarial, introdução à administração, matemática básica, metodologia do trabalho científico, ciências políticas e teoria geral do estado, direito civil, economia e noções de direito econômico e outras. Similarmente, Nasu (2018), em estudo com alunos de contabilidade, obteve evidências de relação positiva entre a quantidade de livros lidos e a performance discente. Entretanto, é preciso alertar que a leitura extracurricular deve ser feita com moderação, já que se realizada de forma demasiada pode prejudicar o desempenho acadêmico (Chen, 2007). Mesmo assim, é importante que os discentes tenham em mente que, ainda que não seja acadêmica, a leitura extracurricular é um componente essencial para o seu sucesso e, portanto, a sua prática deve ser regular e sem excessos.

\subsection{Pesquisas correlatas}

Esta subseção pretende descrever estudos prévios que são pertinentes para entender o papel da leitura e a sua relação com o desempenho acadêmico de estudantes universitários. Adicionalmente, servem de base para a discussão dos achados desta pesquisa, bem como evidencia a necessidade de pesquisas sobre a leitura extracurricular com estudantes da área de ciências sociais aplicadas. Na sequência, descrevem-se as pesquisas.

Em uma universidade dos Estados Unidos, Gallik (1999) investigou a relação entre a leitura recreacional e a performance acadêmica com 151 discentes. Os dados foram coletados por meio de surveys, das quais 13 foram inutilizadas. Desta forma, a amostra final contou com 138 observações. Os testes estatísticos indicaram que há correlação positiva entre a leitura recreacional e o desempenho discente (mensurado pela média geral acumulada), sustentando a hipótese do estudo.

Oliveira e Santos (2005) analisaram a relação entre compreensão em leitura, performance acadêmica e avaliação da aprendizagem. A amostra foi constituída por 270 discentes dos cursos de administração, direito e psicologia dos períodos diurno e noturno de uma instituição particular do interior paulista. Questionários e o teste de Cloze foram aplicados para a coleta dos dados. As evidências obtidas a partir dos procedimentos estatísticos sustentaram uma relação positiva entre as três variáveis.

Oliveira e Santos (2006) examinaram a relação entre a compreensão de leitura e desempenho acadêmico de 270 estudantes dos cursos de administração, direito e psicologia de uma universidade particular. O teste de Cloze, em sua versão tradicional, foi empregado para verificar a compreensão de leitura dos participantes. As análises estatísticas apontaram que houve uma relação positiva entre a compreensão de leitura e o desempenho acadêmico. 
Chen (2007) teve acesso a dados de duas surveys nacionais de Taiwan, uma aplicada com estudantes do primeiro ano de graduação e a outra com os do terceiro ano. Especificamente no que tange à análise da relação entre a leitura extracurricular e o desempenho acadêmico, foi identificada uma correlação negativa. Uma possível explicação para este achado é que os estudantes investigados a realizavam de forma excessiva, ponto que era, inclusive, motivo de preocupação de seus pais. Por isso, a prática demasiada de leitura de conteúdos não acadêmicos pode prejudicar a performance acadêmica.

Lieurya et al. (2014) examinaram, por meio de surveys com 27.000 alunos do ensino fundamental, o efeito do uso de vídeo games (ex: esportes, de estratégia, de tabuleiro etc.) e de atividades de leitura (ex: revistas, jornais, fantasia etc.) na performance cognitiva e acadêmica. Os resultados mostraram que, enquanto os vídeo games não estão significativamente correlacionados com a performance acadêmica, a leitura possui relação positiva. Destaca-se, no entanto, que a relação é pequena. Ainda assim, constatou-se que a leitura de diferentes materiais pode assistir mais o desempenho acadêmico do que os vídeo games.

Nasu (2018) examinou a leitura extracurricular e a sua relação com o desempenho e com o tempo de estudo de alunos de contabilidade. Os dados foram coletados do Enade 2015, cuja amostra foi de 53.887 estudantes. Os resultados indicaram que a leitura extracurricular está positivamente associada ao desempenho e ao tempo de estudo extraclasse.

Alhammada e Ku (2019) conduziram uma pesquisa qualitativa com 20 alunos de pós-graduação de uma universidade estadunidense sobre o uso de $e$-books para a aprendizagem acadêmica. De modo geral, os participantes reportaram que preferem usar e-books a textos físicos. Todavia, ao se preparar para uma prova, os alunos só substituirão sua familiaridade com o texto impresso por um $e$-book se este oferecer conteúdo semelhante e possuir recursos adicionais.

Nascimento et al. (2019) investigaram a contribuição do hábito de leitura para a formação profissional de estudantes de contabilidade a partir do teste de Cloze e da escala de funções de leitura. A amostra foi composta por 180 estudantes de uma IES de Fortaleza (CE). Os resultados do teste de Cloze indicaram que os estudantes apresentaram dificuldade de compreensão textual, e os achados da escala de funções de leitura apontaram um maior uso das funções "aprendizagem" e "utilidade". Concluiu-se, portanto, que há um ambiente propício para o aprimoramento das competências profissionais, mesmo que as funções "moralidade" e "estímulo" ainda demandem incentivo para superarem as barreiras de compreensão de leitura.

Levine et al. (2020) analisaram se a leitura recreacional é benéfica à saúde mental e o que motiva esta leitura. Ao todo, 231 alunos de uma universidade canadense participaram do estudo. Os resultados sustentaram que há relação positiva entre a leitura recreacional e a saúde mental, bem como estudantes que são motivados autonomamente estão mais propensos a praticar a leitura de livros de forma recreativa.

Com base nesta revisão de literatura, observou-se que a compreensão em leitura constitui fator crucial para a performance acadêmica de estudantes universitários. É argumentável que tal compreensão é aperfeiçoada à medida que os estudantes praticam a leitura, seja curricular ou extracurricular. Portanto, com base nas evidências da literatura prévia, espera-se encontrar uma relação positiva entre a leitura, mesmo em caráter de extracurricularidade, e o desempenho discente. Ademais, nota-se uma lacuna de pesquisas sobre a leitura de livros extracurriculares relacionados ao campo de ciências sociais aplicadas, cujos cursos - administração, direito e ciências contábeis, por exemplo - estão entre os mais procurados nacionalmente. Portanto, é de valor que se examine o papel deste tipo de leitura na aprendizagem dos estudantes do referido campo. 


\section{Metodologia}

\subsection{Dados, população e amostra}

Os dados utilizados nesta pesquisa foram coletados do endereço eletrônico do Instituto Nacional de Estudos e Pesquisas Educacionais Anísio Teixeira (INEP, 2019) e são referentes ao Enade de 2018. Para a seleção dos cursos da área de ciências sociais aplicadas, foram considerados aqueles constantes no endereço eletrônico do currículo Lattes (Conselho Nacional de Desenvolvimento Científico e Tecnológico, 2019). No entanto, cabe ressaltar que o Enade 2018 não era obrigatório para todos os cursos desta lista. Por esta razão, a quantidade de cursos analisada nesta pesquisa é mais restrita. Apesar disso, foram considerados nove cursos de graduação, quais sejam: administração (ADM), direito (DIR), economia (ECO), contabilidade (CON), turismo (TUR), serviço social (SES), administração pública (ADP), comunicação social - jornalismo (CSJ) e comunicação social - publicidade e propaganda (CSP).

O Enade visa avaliar a qualidade dos cursos de graduação do Brasil por meio da análise do desempenho acadêmico dos estudantes. O exame é composto por questões de formação geral (ex: responsabilidade social) - comuns a todos os cursos - e específicas de cada curso. Para estudantes de contabilidade, por exemplo, uma questão específica poderia demandar conhecimentos de teoria da contabilidade, conteúdo que dificilmente seria requisitado pelas questões específicas de outros cursos. Desta forma, o desempenho do aluno é calculado por meio da média ponderada das notas nas provas de componente específico (75\%) e de formação geral (25\%).

Os discentes dos referidos cursos que realizaram o Enade 2018 representam a população da pesquisa, totalizando 398.859 estudantes. Posteriormente à identificação da população, foram realizadas etapas para o tratamento dos dados. Mais especificamente, seis etapas de exclusão de observações foram executadas por razões distintas, quais sejam: (1) ausente (código 222); (2) participação indevida (código 334); (3) ausente devido à dupla graduação (código 444); (4) resultado desconsiderado pela aplicadora (código 556); (5) participante com prova entregue integralmente em branco (código 333); e (6) apresentação da codificação "não aplicável" (N/A) nas variáveis de desempenho acadêmico (nota geral, nota de formação geral e nota de componente específico), mesmo após as etapas prévias de exclusão. A amostra final é composta por 338.977 estudantes, os quais representam 85\% da população. A Tabela 1 fornece mais detalhamentos da população, amostra e etapas de exclusão.

Tabela 1

População, amostra e etapas de exclusão: geral e por curso

\begin{tabular}{lcccccccccc}
\hline \multicolumn{1}{c}{ Curso } & ADM & DIR & ECO & CON & TUR & SES & ADP & CSJ & CSP & Total \\
\hline População & 120.405 & 145.425 & 9.582 & 62.475 & 3.328 & 24.625 & 4.306 & 11.447 & 17.266 & 398.859 \\
\hline (1) Ausente & $(20.628)$ & $(17.906)$ & $(1.497)$ & $(9.502)$ & $(625)$ & $(3.222)$ & $(816)$ & $(1.645)$ & $(3.274)$ & $(59.115)$ \\
\hline $\begin{array}{l}\text { (2) Participação indevida } \\
\text { (3) Ausente devido à }\end{array}$ & $(38)$ & $(2)$ & $(9)$ & & $(8)$ & & & $(3)$ & $(95)$ \\
\begin{tabular}{l} 
dupla graduação \\
\hline
\end{tabular} & $(126)$ & $(95)$ & $(8)$ & $(107)$ & $(3)$ & $(8)$ & $(9)$ & $(6)$ & $(7)$ & $(369)$ \\
\hline
\end{tabular}

\begin{tabular}{|c|c|c|c|c|c|c|c|c|c|c|}
\hline $\begin{array}{l}\text { (4) Resultado } \\
\text { desconsiderado pela } \\
\text { aplicadora }\end{array}$ & (1) & (1) & & & & (1) & & & 0 & (3) \\
\hline (5) Prova em branco & (81) & (71) & (22) & (26) & & (28) & (5) & $(20)$ & (2) & $(255)$ \\
\hline (6) N/A em desempenho & $(15)$ & & (4) & $(10)$ & (4) & (4) & (2) & (3) & (3) & $(45)$ \\
\hline (=) Amostra & 99.519 & 127.314 & 8.049 & 52.821 & 2.696 & 21.354 & 3.474 & 9.773 & 13.977 & 338.977 \\
\hline$\%(A)$ & 82,7 & 87,5 & 84,0 & 84,5 & 81,0 & 86,7 & 80,7 & 85,4 & 81,0 & 85,0 \\
\hline
\end{tabular}

Nota. ${ }^{(A)}$ Representatividade da amostra em relação à população do estudo.

Foi executada a análise de outliers multivariados considerando p-value de 0,15 por meio do blocked adaptive computationally efficient outlier nominators (Billor, Hadi, \& Velleman, 2000; Weber, 2010). Conforme o resultado da análise, não foram identificados outliers multivariados. 


\subsection{Variáveis da pesquisa}

Em alinhamento ao objetivo de pesquisa, foram coletados dados de desempenho acadêmico - em particular, da nota geral (NTGE), da nota de componente específico (NTCE) e da nota de formação geral (NTFG) - e da variável de leitura de livros extracurriculares, que corresponde à quantidade de livros lidos no ano de 2018 que não constaram na bibliografia das disciplinas (LIVRO). Adicionalmente, coletou-se a variável REFER, que representa a percepção discente do quão relevante foi a indicação das referências bibliográficas contidas nas disciplinas dos cursos. Tanto a proxy para leitura de livros extracurriculares (LIVRO) como a de relevância das referências (REFER) foram utilizadas por estudo prévio (Nasu, 2018). A Tabela 2 mostra a descrição das variáveis da pesquisa.

Tabela 2

Variáveis da pesquisa

\begin{tabular}{|c|c|c|}
\hline Sigla & Descrição & Mensuração(B) \\
\hline NTGE & Nota geral do aluno no Enade 2018 & 0 a 100 pontos. \\
\hline NTCE & Nota de componente específico do aluno no Enade 2018 & 0 a 100 pontos. \\
\hline NTFG & Nota de formação geral do aluno no Enade 2018 & 0 a 100 pontos. \\
\hline LIVRO & $\begin{array}{l}\text { "Excetuando-se os livros indicados na bibliografia do seu } \\
\text { curso, quantos livros você leu neste ano?" (Questão } 22 \text { do } \\
\text { Questionário do Estudante do Enade 2018) }\end{array}$ & $\begin{array}{l}0 \text { livro; } 1-2 \text { livros; 3-5 livros; } 6-8 \text { livros; acima } \\
\text { de } 8 \text { livros. }\end{array}$ \\
\hline REFER & $\begin{array}{l}\text { "As referências bibliográficas indicadas pelos professores } \\
\text { nos planos de ensino contribuíram para seus estudos e } \\
\text { aprendizagens" (Questão } 39 \text { do Questionário do Estudante } \\
\text { do Enade 2018) }\end{array}$ & $\begin{array}{l}1 \text { (discordo totalmente) a } 6 \text { (concordo } \\
\text { totalmente) pontos. }\end{array}$ \\
\hline CURSO & Curso do aluno & $\begin{array}{l}9 \text { categorias (ADM, DIR, ECO, CON, TUR, SES, } \\
\text { ADP, CSJ ou CSP). }\end{array}$ \\
\hline MODAL & Modalidade de ensino & Presencial ou EAD. \\
\hline REGIAO & Região do curso & 5 categorias $(\mathrm{N}, \mathrm{NE}, \mathrm{S}, \mathrm{SE}$ ou $\mathrm{CO})(\mathrm{C})$. \\
\hline TURNO & Turno do curso & $\begin{array}{l}4 \text { categorias (Integral, Matutino, Vespertino } \\
\text { ou Noturno). }\end{array}$ \\
\hline IDADE & Idade do aluno & Em anos completos. \\
\hline SEXO & Sexo do aluno & Masculino ou Feminino. \\
\hline ECIVIL & Estado civil do aluno & $\begin{array}{l}5 \text { categorias (Solteiro, Casado, Divorciado, } \\
\text { Viúvo ou Outro). }\end{array}$ \\
\hline ETNIA & Etnia do aluno & $\begin{array}{l}5 \text { categorias (Branca, Negra, Amarela, Parda, } \\
\text { Indígena e Não declarada)(A). }\end{array}$ \\
\hline RENDA & Renda mensal da família do aluno & $\begin{array}{l}\text { 0-3 salários mínimos (SM), 4-6 salários } \\
\text { mínimos ou acima de } 6 \text { salários mínimos. }\end{array}$ \\
\hline HOEST & Horas de estudo extraclasse & $\begin{array}{l}0 \text { horas; } 1-3 \text { horas; } 4-7 \text { horas; } 8-12 \text { horas ou } \\
\text { acima de } 12 \text { horas. }\end{array}$ \\
\hline
\end{tabular}

Nota. (A)Os estudantes que optaram por não declarar a sua etnia foram eliminados das análises que se utilizam dessa variável a fim de evitar problemas na interpretação dos dados.

(B)Para as variáveis qualitativas, a categoria em negrito representa a categoria de referência utilizada para fins de análise dos modelos de regressão (capítulo seguinte).

(c) $\mathrm{SE}=$ Sudeste; $\mathrm{S}=$ Sul; N = Norte; NE = Nordeste; CO = Centro-Oeste.

Além do desempenho acadêmico e da variável de interesse, foram coletadas variáveis de controle para precisar mais as análises. As variáveis de controle são curso (CURSO), modalidade de ensino (MODAL), região do curso (REGIAO), turno do curso (TURNO), idade (IDADE), sexo (SEXO), estado civil (ECIVIL), etnia (ETNIA), renda familiar mensal (RENDA) e horas de estudo (HOEST). 


\subsection{Técnicas de análise de dados}

Posteriormente às fases de seleção e coleta das variáveis, procedeu-se à etapa de análise dos dados. Foram conduzidas estatísticas descritivas das variáveis quantitativas e qualitativas. Na sequência, foram elaboradas tabelas cruzadas entre as variáveis LIVRO e CURSO e foi realizado o teste de associação com base no valor qui-quadrado. Por fim, foram utilizados modelos de regressão para a análise da relação entre a leitura de livros extracurriculares e o desempenho discente por permitir verificar o efeito de variáveis explicativas sobre uma variável explicada (Fávero, 2015; Gordon, 2015), sendo apropriados ao objetivo desta pesquisa. Portanto, foram desenvolvidos três modelos de regressão, os quais estão representados na Equação (1), (2) e (3) a seguir:

$$
\begin{aligned}
& \operatorname{DES}_{\mathrm{i}}=\mathrm{a}_{\mathrm{i}}+\beta_{1} \cdot \operatorname{LIVRO}_{\mathrm{i}}+\varepsilon_{\mathrm{i}} \quad \text { Equação (1) } \\
& \operatorname{DES}_{\mathrm{i}}=\mathrm{a}_{\mathrm{i}}+\beta_{1} \cdot \mathrm{LIVRO}_{\mathrm{i}}+\beta_{2} \cdot \operatorname{REFER}_{\mathrm{i}}+\beta_{3} \cdot \text { CONTROLES }_{\mathrm{i}}+\varepsilon_{\mathrm{i}} \quad \text { Equação (2) } \\
& \mathrm{NTFG}_{\mathrm{i}}=\mathrm{a}_{\mathrm{i}}+\beta_{1} \cdot \text { LIVRO }_{\mathrm{i}}+\beta_{2} \cdot \text { CURSO }_{\mathrm{i}}+\beta_{3} \cdot \text { CONTROLES }_{\mathrm{i}}+\varepsilon_{\mathrm{i}} \quad \text { Equação (3) }
\end{aligned}
$$

A variável dependente (DES) é o desempenho do aluno, que pode ser a NTGE, NTCE ou NTFG. A Equação (1) é um modelo de regressão múltipla, o qual considera apenas as dummies relacionadas à variável LIVRO. Visa-se, portanto, capturar os efeitos da leitura de livros extracurriculares de forma individual, sem a presença de outros fatores explicativos. Por outro lado, a Equação (2) procura examinar a existência de relação entre a leitura de livros extracurriculares e o desempenho acadêmico quando a variável REFER e os outros controles são inseridos (MODAL, REGIAO, TURNO, IDADE, SEXO, ECIVIL, ETNIA, RENDA e HOEST). As variáveis qualitativas foram transformadas em $\mathrm{N}-1$ dummies ( $\mathrm{N}$ = número de categorias da variável qualitativa), conforme orienta Fávero (2015). A categoria de referência se encontra negritada na Tabela 2. Por último, a Equação (3) busca analisar o impacto das variáveis LIVRO e CURSO na NTFG, em conjunto com as variáveis de controle. Salienta-se que foi usada a NTFG porque as suas questões são comuns aos estudantes de todos os cursos, diferentemente da NTCE (questões específicas) e da NTGE (que é composta por $75 \%$ da nota da prova de componente específico e $25 \%$ da de formação geral). Os modelos de regressão foram estimados por Mínimos Quadrados Ordinários (MQO) com errospadrão robustos para heterocedasticidade. Ademais, empregou-se o Variance Inflation Factor (VIF) para observar a multicolinearidade dos modelos.

As estimações por MQO com erros-padrão "tradicionais" (não robustos) também foram efetuadas e produziram resultados muito similares. Entretanto, por cautela, somente os resultados das regressões com erros-padrão robustos são reportados na seção seguinte. Adicionalmente, destaca-se que as variáveis de nível educacional do pai e da mãe foram coletadas e inseridas nos modelos. Os principais achados (relacionados à variável LIVRO) foram muito semelhantes aos reportados.

Um último ponto concerne à endogeneidade (mais especificamente, a da correlação reversa), uma vez que poder-se-ia supor que alunos com capacidades cognitivas mais elevadas possuem melhor desempenho e, por sua vez, poderiam demandar maior quantidade de leitura. Logo, alguém poderia presumir que seria o desempenho acadêmico que afeta a leitura. Entretanto, os autores da presente pesquisa acreditam que a correlação reversa, neste estudo, é pouco plausível. Os alunos fazem o Enade e respondem ao Questionário do Estudante próximo ao término do curso de graduação (alunos concluintes). No caso, os alunos tinham até o dia 21/11/2018 para o preenchimento do questionário e a aplicação do Enade 2018 ocorreu no dia 25/11/2018, conforme cronograma divulgado no Diário Oficial da União (INEP, 2018). Por isso, os alunos responderam à questão 22 do Questionário do Estudante com base na leitura de livros feita antes da realização do exame. Consequentemente, é a leitura que afeta o desempenho discente. 


\section{Resultados}

A Tabela 3 mostra as estatísticas descritivas das variáveis da pesquisa. O Painel A retrata as variáveis quantitativas, em que se observa que o desempenho geral médio dos estudantes de ciências sociais aplicadas no Enade 2018 é de 40,6 pontos, com desvio-padrão (DP) de 14,3 pontos. O desempenho médio na prova de componente específico foi de 46,1 pontos ( $\mathrm{DP}=17,6$ pontos) e na prova de formação geral foi de 38,7 pontos ( $\mathrm{DP}=15,4$ pontos). O desempenho superior na prova de componente específico é esperado, já que o discente se especializa no conteúdo específico de seu curso de graduação. A idade média dos estudantes da amostra é de 28,8 anos ( $\mathrm{DP}=7,9$ anos), indicando que são relativamente jovens, ainda que se identifique idosos (máximo $=83,0$ anos). Também é surpreendente que um aluno da amostra tenha 11 anos (mínimo). Quanto à variável REFER, verifica-se que os discentes reportaram que as referências contidas na bibliografia das disciplinas foram relevantes para o seu aprendizado (média $=5,0$ pontos; $\mathrm{DP}=1,3$ ponto).

Tabela 3

\section{Estatísticas descritivas das variáveis da pesquisa}

\begin{tabular}{|c|c|c|c|c|c|c|}
\hline Painel A: Variáveis quantitativas & $\mathbf{N}$ & Média & DP & Mínimo & Máximo & Mediana \\
\hline NTGE & 338.997 & 40,6 & 14,3 & 0,0 & 92,8 & 39,5 \\
\hline NTCE & 338.997 & 46,1 & 17,6 & 0,0 & 98,6 & 45,4 \\
\hline NTFG & 338.997 & 38,7 & 15,4 & 0,0 & 97,5 & 37,6 \\
\hline IDADE & 338.997 & 28,8 & 7,9 & 11,0 & 83,0 & 26,0 \\
\hline REFER & 332.089 & 5,0 & 1,3 & 1,0 & 6,0 & 5,0 \\
\hline Painel B: Variáveis qualitativas(A) & FA & FR & & & FA & FR \\
\hline \multicolumn{7}{|l|}{ MODAL } \\
\hline A distância & 49.308 & 14,6 & Preser & & 289.669 & 85,5 \\
\hline \multicolumn{7}{|l|}{ REGIAO } \\
\hline SE & 147.549 & 43,5 & $\mathrm{~S}$ & & 76.695 & 22,6 \\
\hline $\mathrm{N}$ & 19.193 & 5,7 & $\mathrm{CO}$ & & 30.247 & 8,9 \\
\hline $\mathrm{NE}$ & 65.293 & 19,3 & & & & \\
\hline \multicolumn{7}{|l|}{ SEXO } \\
\hline Feminino & 202.398 & 59,7 & Mascu & & 136.579 & 40,3 \\
\hline \multicolumn{7}{|l|}{ TURNO } \\
\hline Integral & 23.314 & 6,9 & Vespe & & 10.698 & 3,2 \\
\hline Matutino & 57.379 & 16,9 & Notur & & 247.586 & 73,0 \\
\hline \multicolumn{7}{|l|}{ ECIVIL } \\
\hline Solteiro & 243.740 & 72,3 & Viúvo & & 972 & 0,3 \\
\hline Casado & 70.273 & 20,9 & Outro & & 11.537 & 3,4 \\
\hline Divorciado & 10.550 & 3,1 & & & & \\
\hline \multicolumn{7}{|l|}{ ETNIA } \\
\hline Branca & 180.641 & 54,5 & Parda & & 111.650 & 33,7 \\
\hline Negra & 30.159 & 9,1 & Indíge & & 972 & 0,3 \\
\hline Amarela & 7.835 & 2,4 & & & & \\
\hline \multicolumn{7}{|l|}{ RENDA } \\
\hline 0-3 salários mínimos & 156.451 & 46,4 & +6 salc & nínimos & 70.863 & 21,0 \\
\hline 4-6 salários mínimos & 109.758 & 32,6 & & & & \\
\hline \multicolumn{7}{|l|}{ LIVRO } \\
\hline 0 livro & 48.365 & 14,4 & $6-8$ livi & & 29.225 & 8,7 \\
\hline 1-2 livros & 122.378 & 36,3 & +8 livr & & 36.713 & 10,9 \\
\hline 3-5 livros & 100.391 & 29,8 & & & & \\
\hline \multicolumn{7}{|l|}{ HOEST } \\
\hline 0 horas & 28.641 & 8,5 & $8-12 \mathrm{~h}$ & & 30.968 & 9,2 \\
\hline 1-3 horas & 161.405 & 47,9 & $12+\mathrm{hc}$ & & 24.730 & 7,3 \\
\hline 4-7 horas & 91.328 & 27,1 & & & & \\
\hline
\end{tabular}

Nota. DP = Desvio-padrão; FA = Frequência absoluta; FR = Frequência relativa (em \%).

(A)As frequências da variável CURSO podem ser encontradas na Tabela 1, por isso não estão reportadas aqui. 
O Painel Bretrata as variáveis qualitativasdo estudo. Os estudantes da amostra são, predominantemente, do ensino presencial (85,5\%), da região Sudeste (43,5\%), do sexo feminino (59,7\%), do turno noturno $(73,0 \%)$, solteiros $(72,3 \%)$, brancos $(54,5 \%)$ e de famílias que recebem de zero a três salários mínimos $(46,4 \%)$. A maioria dos estudantes da amostra leu de um a dois livros ao longo do ano de $2018(36,3 \%)$ e estudou de uma a três horas $(47,9 \%)$ semanalmente.

Na sequência, elabora-se a tabela cruzada das variáveis CURSO e LIVRO, resultando na Tabela 4. Primeiramente, discutem-se os resultados de forma geral e, posteriormente, por curso (comparativamente).

Tabela 4

Tabela cruzada das variáveis CURSO e LIVRO

\begin{tabular}{|c|c|c|c|c|c|c|c|c|c|c|c|c|}
\hline \multirow{2}{*}{$\begin{array}{l}\text { CURSO/ } \\
\text { LIVRO }\end{array}$} & \multicolumn{2}{|c|}{0 livro } & \multicolumn{2}{|c|}{ 1-2 livros } & \multicolumn{2}{|c|}{ 3-5 livros } & \multicolumn{2}{|c|}{ 6-8 livros } & \multicolumn{2}{|c|}{ +8 livros } & \multicolumn{2}{|c|}{ Total } \\
\hline & FA & FR & FA & FR & FA & FR & FA & FR & FA & FR & FA & FR \\
\hline ADM & 16.500 & 16,7 & 40.166 & 40,6 & 26.891 & 27,2 & 7.233 & 7,3 & 8.096 & 8,2 & 98.886 & 100,0 \\
\hline DIR & 14.522 & 11,5 & 40.920 & 32,3 & 41.106 & 32,5 & 12.579 & 9,9 & 17.500 & 13,8 & 126.627 & 100,0 \\
\hline ECO & 1.256 & 15,7 & 2.614 & 32,7 & 2.484 & 31,0 & 693 & 8,7 & 954 & 11,9 & 8.001 & 100,0 \\
\hline CON & 10.317 & 19,6 & 21.247 & 40,4 & 13.298 & 25,3 & 3.505 & 6,7 & 4.233 & 8,0 & 52.600 & 100,0 \\
\hline TUR & 386 & 14,5 & 965 & 36,2 & 840 & 31,5 & 241 & 9,0 & 233 & 8,7 & 2.665 & 100,0 \\
\hline SES & 1.870 & 8,8 & 7.440 & 35,1 & 7.175 & 33,9 & 2.260 & 10,7 & 2.438 & 11,5 & 21.183 & 100,0 \\
\hline ADP & 510 & 14,8 & 1.300 & 37,6 & 981 & 28,4 & 263 & 7,6 & 403 & 11,7 & 3.457 & 100,0 \\
\hline CSJ & 846 & 8,7 & 2.599 & 26,7 & 3.463 & 35,6 & 1.251 & 12,9 & 1.575 & 16,2 & 9.734 & 100,0 \\
\hline CSP & 2.158 & 15,5 & 5.127 & 36,8 & 4.153 & 29,8 & 1.200 & 8,6 & 1.281 & 9,2 & 13.919 & 100,0 \\
\hline Total & 48.365 & 14,3 & 122.378 & 36,3 & 100.391 & 29,8 & 29.225 & 8,7 & 36.713 & 10,9 & 337.072 & 100,0 \\
\hline
\end{tabular}

Nota. FA = Frequência absoluta (quantidade de estudantes); FR = Frequência relativa (em \%).

Para realizar as FRs, foi tomada como base a FA da última coluna da tabela (Total).

De forma geral, a maioria dos discentes declararam que leram de um a dois livros ao longo do ano de $2018(\mathrm{~N}=122.378 ; 36,3 \%)$. Estudantes que reportaram ler de três a cinco livros também representam percentual relevante $(\mathrm{N}=100.391 ; 29,8 \%)$. Salienta-se que 48.365 estudantes $(14,3 \%)$ não leram sequer um livro ao longo de 2018. Este resultado é preocupante porque pode indicar deficiência no desenvolvimento de habilidades de leitura, escrita e interpretação de textos dos discentes, aspectos fundamentais para se obter sucesso nos cursos de graduação (Oliveira \& Santos, 2005). Ao consultar a Tabela 3, observa-se que a maioria dos estudantes estão inscritos no turno noturno, sugerindo que há maior oferta de vagas neste período ou que os estudantes estão trabalhando, o que é usual para concluintes do curso de graduação. Desta forma, pode ser que parte significativa dos estudantes trabalhe durante o dia e estude à noite, o que resultaria em menor tempo para leitura.

Outra explicação pode ser a falta de recursos financeiros para adquirir livros. Como visto na Tabela 3, a maioria dos estudantes pertence a famílias que têm de zero a três salários mínimos, cuja renda é usada integralmente para custear as necessidades básicas de seus membros. A esse respeito, a sugestão é que o aluno frequente bibliotecas públicas para efetuar a prática da leitura. Complementarmente, existe a dificuldade em alocar o tempo livre em atividades de leitura, já que os estudantes podem preferir ficar escutando música, navegando na internet ou se conectando às redes sociais (Mokhtari et al., 2009). Da mesma forma, há evidências de que a leitura é superior ao uso do vídeo game para a performance discente (Lieurya et al. (2014). Por isso, uma mudança de hábito pode ser necessária para que haja a inserção e manutenção da prática de leitura na vida cotidiana dos estudantes. Finalmente, constatam-se menores frequências para as categorias de seis a oito livros $(\mathrm{N}=29.225 ; 8,7 \%)$ e acima de oito livros $(\mathrm{N}=36.713$; 10,9\%). Esse achado também preocupa, uma vez que nem 20\% de um total de 337.072 estudantes de ciências sociais aplicadas chegaram à marca de seis ou mais livros no ano de 2018. 
Quando se realiza a análise por curso de graduação, verifica-se que a maioria dos estudantes de todos os cursos pesquisados reportaram ler de um a dois livros, com exceção dos estudantes de DIR e CSJ, cuja maioria declarou ler de três a cinco livros (DIR $=41.106$ estudantes; 32,5\%; CSJ $=3.463$ estudantes; $35,6 \%$ ). Estudantes de ADM, CON e TUR foram os que menos leram mais de oito livros (ADM = 8.096 estudantes; 8,2\%; $\mathrm{CON}=4.233$ estudantes; $8,0 \%$; TUR $=233$ estudantes; 8,7\%). Ainda, estudantes de $\mathrm{ADM}, \mathrm{COM}$ e ADP também estão dentre os que menos leram de seis a oito livro (ADM = 7.233 estudantes; $7,3 \% ; \mathrm{CON}=3.505$ estudantes; $6,7 \% ; \mathrm{ADP}=263$ estudantes; 7,6\%). Esses achados sugerem que há espaço para o aprimoramento e prática da leitura por parte dos estudantes de negócios.

Há que se chamar atenção para o curso de CON, visto que possui o maior percentual de zero livros (10.317 estudantes; $19,6 \%$ ). Desta forma, o curso de CON possui altos percentuais em categorias de baixa frequência de leitura e pequenos percentuais em categorias de alta frequência de leitura. Estes achados sobre a leitura de livros extracurriculares dos discentes de contabilidade podem ajudar a explicar o motivo das reduzidas taxas de aprovação no Exame de Suficiência para a conquista da carteira de habilitação profissional e o baixo desempenho em avaliações da qualidade do ensino superior, como o Enade. Embora não sejam leituras acadêmicas, a prática de leitura de materiais extracurriculares pode assistir os estudantes no aperfeiçoamento de sua escrita e interpretação de texto, competências importantes para o exercício profissional e aprovação em exames profissionais, em especial por tais avaliações apresentarem questões de português cujos enunciados usualmente envolvem a leitura de textos.

Os estudantes do curso de CSJ, por outro lado, são os que, proporcionalmente, reportaram ler mais ao longo de 2018. Este curso obteve os maiores percentuais nas categorias de seis a oito livros (12,9\%) e acima de oito livros (16,2\%) e o menor percentual na categoria zero livros $(8,7 \%)$ em relação aos demais cursos de ciências sociais aplicadas. Por ser um curso de jornalismo, é possível que os discentes estejam em constante prática de leitura, seja relacionada ou não ao curso. Por fim, foi conduzido o teste qui-quadrado para verificar se há uma associação significante entre CURSO e LIVRO. Conforme o resultado do teste, constatou-se que estão significativamente relacionados (chi2 $=8.900,00 ; \mathrm{p}<0,01)$. Logo, enquanto alguns cursos estão associados a categorias de leitura de menor frequência (ex: $\mathrm{CON}$ ), outros estão associados a categorias de leitura de maior frequência (ex: CSJ). O curso de CON, por possuir leitores menos ávidos, pode e deve encorajar leituras extracurriculares. Na sequência, analisa-se a relação entre a leitura de livros e o desempenho acadêmico. A Tabela 5 reporta os resultados das Equações (1) e (2). Gordon (2015) aponta que VIFs iguais a 4 e 10 são às vezes considerados altos e, de acordo com Yan e Su (2013), VIFs acima de 10 podem indicar problemas de multicolinearidade. Como os VIFs médios dos modelos desta pesquisa estão abaixo de 2 , sugere-se que há baixa multicolinearidade. 
Tabela 5

Resultados dos modelos de regressão (1) e (2)

\begin{tabular}{|c|c|c|c|c|c|c|}
\hline \multirow{2}{*}{$\begin{array}{l}\text { VAR. DEP. } \\
\text { EQUAÇÃO(B) }\end{array}$} & \multicolumn{2}{|c|}{ NTFG } & \multicolumn{2}{|c|}{ NTCE } & \multicolumn{2}{|c|}{ NTGE } \\
\hline & (1) & (2) & (1) & (2) & (1) & (2) \\
\hline & $\begin{array}{l}\text { Coeficiente } \\
\text { (EPR) }\end{array}$ & $\begin{array}{l}\text { Coeficiente } \\
\text { (EPR) }\end{array}$ & $\begin{array}{l}\text { Coeficiente } \\
\text { (EPR) }\end{array}$ & $\begin{array}{l}\text { Coeficiente } \\
\text { (EPR) }\end{array}$ & $\begin{array}{l}\text { Coeficiente } \\
\text { (EPR) }\end{array}$ & $\begin{array}{l}\text { Coeficiente } \\
\text { (EPR) }\end{array}$ \\
\hline \multirow{2}{*}{ CONSTANTE } & 44,763 & 49,707 & 37,802 & 41,042 & 39,555 & 43,221 \\
\hline & $(0,080)$ & $(0,225)$ & $(0,069)$ & $(0,197)$ & $(0,064)$ & $(0,181)$ \\
\hline \multirow{2}{*}{ LIVRO (1-2 livros) } & 0,161 * & $0,572 * \star \star$ & $-0,047$ & $-0,198$ & 0,005 & $-0,006$ \\
\hline & $(0,094)$ & $(0,099)$ & $(0,082)$ & $(0,086)$ & $(0,076)$ & $(0,078)$ \\
\hline \multirow{2}{*}{ LIVRO (3-5 livros) } & $2,114 * * *$ & $1,978 * * *$ & $1,360 * * *$ & $0,637 * * *$ & $1,548 * * *$ & $0,972 * * \star$ \\
\hline & $(0,098)$ & $(0,104)$ & $(0,085)$ & $(0,090)$ & $(0,078)$ & $(0,083)$ \\
\hline \multirow{2}{*}{ LIVRO (6-8 livros) } & $2,484 * * *$ & $1,968^{* * *}$ & $1,748 * * *$ & $0,614 * * *$ & $1,932 * * *$ & $0,953 * * *$ \\
\hline & $(0,131)$ & $(0,134)$ & $(0,115)$ & $(0,118)$ & $(0,107)$ & $(0,108)$ \\
\hline \multirow{2}{*}{ LIVRO (+8 livros) } & $4,403 * \star *$ & $3,115^{* \star *}$ & $3,291 * * *$ & $1,431 * * *$ & $3,569 * * *$ & $1,852 * * *$ \\
\hline & $(0,125)$ & $(0,131)$ & $(0,109)$ & $(0,115)$ & $(0,102)$ & $(0,106)$ \\
\hline \multirow{2}{*}{ REFER } & & $-0,731$ *** & & $-0,294^{* \star *}$ & & $-0,403^{* * *}$ \\
\hline & & $(0,026)$ & & $(0,022)$ & & $(0,021)$ \\
\hline OUTROS CONTROLES(A) & Não & Sim & Não & Sim & Não & Sim \\
\hline$N^{(C)}$ & 337.072 & 326.500 & 337.072 & 326.500 & 337.072 & 326.500 \\
\hline F/Prob $>F$ & $546,89 / 0,00$ & $1.335,78 / 0,00$ & $407,50 / 0,00$ & $1.054,44 / 0,00$ & $548,64 / 0,00$ & $1.409,74 / 0,00$ \\
\hline $\mathrm{R}^{2}$ & 0,0067 & 0,1042 & 0,0051 & 0,0835 & 0,0068 & 0,1093 \\
\hline VIF médio & 1,86 & 1,74 & 1,86 & 1,74 & 1,86 & 1,74 \\
\hline
\end{tabular}

Nota. VAR. DEP. = variável dependente. EPR = Erro-padrão robusto. Estão entre parênteses.

(A)Para fins de concisão e foco, os resultados concernentes às variáveis de controle foram omitidos. Favor consultar o Apêndice I para observar a tabela completa.

(B)Os modelos de regressão possuem menos observações do que a amostra inteira devido aos missing values das variáveis.

***, ** e * representam o nível de significância a 1\%,5\% e 10\%, respectivamente.

Com base nos resultados das Equações (1) e (2), observa-se que a variável LIVRO possui relação positiva com as variáveis de desempenho (NTFG, NTCE, NTGE). Analisando a Equação (1), que tem a NTFG como variável dependente, identificou-se que estudantes que reportaram ler acima de oito livros $(+8$ livros) desempenharam, em média, 4,403 pontos a mais na prova de formação geral do que aqueles que não leram livros (0 livro - categoria de referência). Da mesma forma, estudantes que leram de seis a oito livros (6-8 livros) desempenharam, em média, 2,484 pontos a mais na prova de formação comparativamente aos que não leram sequer um livro (0 livro). Mesmo os estudantes que leram de um a dois livros (1-2 livros) performaram melhor (coeficiente $=0,161 ; \mathrm{p}<0,10$ ) na prova de formação geral do que os que não leram nada. A mesma interpretação pode ser feita para os coeficientes dos demais modelos de regressão. Nota-se que os discentes que declararam ler mais de oito livros (+8 livros) obtiveram performances significativamente maiores do que aqueles que não leram nenhum (0 livro), sugerindo que a leitura, mesmo de cunho extracurricular, é relevante para se obter desempenhos acadêmicos mais elevados. Este achado é consistente com o de Gallik (1999) e Nasu (2018), os quais também detectaram relação positiva entre leitura extracurricular e performance acadêmica. 
Para NTCE e NTGE, a categoria de um a dois livros (1-2 livros) não se mostrou estatisticamente diferente de zero $(p>0,10)$. Isso sugere que estudantes que leem de um a dois livros de cunho extracurricular não têm, em média, melhor desempenho do que estudantes que não leem livros (0 livro). A prova de componente específico possui questões particulares de cada curso. Logo, leituras não relacionadas aos cursos - extracurriculares - somente serão efetivas para melhorar a performance discente se realizadas de forma mais intensa (três livros ou mais). Como a nota na prova de componente específico (NTCE) tem peso de $75 \%$ na nota geral (NTGE), o efeito se estende para o desempenho geral do aluno. Por outro lado, observa-se que, para a NTFG, a leitura de livros extracurriculares afeta positivamente a performance.

Este resultado sugere que tal tipo de leitura colabora para aumentar o desempenho em provas que envolvem conhecimento de formação geral. À medida que o estudante passa a ler sobre conteúdos que ultrapassam os limites do que está sendo especificamente aprendido no curso de graduação, a sua formação geral pode estar sendo aprimorada e, por esta razão, o seu desempenho em provas de conteúdo geral tende a ser maior. Esse debate é consistente com os resultados de Silva e Santos (2004), os quais indicaram uma associação positiva entre compreensão em leitura de performance discente de alunos de oito cursos universitários. A leitura extracurricular contribui para uma formação mais multidisciplinar, em que os alunos podem possuir visões mais holísticas quando da atuação profissional. Kuimova e Ukhov (2016), por exemplo, sustentam que este tipo de leitura traz benefícios ao se aprender línguas estrangeiras, especialmente por aprimorar habilidades de empatia, independência e sociais dos estudantes.

Um resultado contraintuitivo está relacionado à percepção discente sobre a assistência acadêmica provida pelas referências bibliográficas recomendadas pelos professores (REFER). As Equações (2) da Tabela 5 mostram que há relação negativa entre REFER e as três variáveis de desempenho (NTFG, NTCE e NTGE). Portanto, ainda que os estudantes acreditem que as referências sugeridas pelos docentes ajudam a melhorar a aprendizagem (ver Tabela 3 - Painel A), essa crença não se reflete no desempenho acadêmico. Por esta razão, é importante cruzar medidas mais subjetivas (REFER) e medidas mais objetivas (NTFG, NTCE e NTGE). Reforçam-se, aqui, algumas potenciais explicações acerca da variável REFER. Primeiro, estudantes que possuem melhor desempenho tendem a consultar e ler mais as referências bibliográficas dos cursos e, da mesma forma, podem ter níveis de criticidade mais elevados. Segundo, as referências bibliográficas podem estar desalinhadas aos conteúdos programáticos exigidos pelo ENADE.

Apesar das Equações (1) e (2) apresentarem variáveis explicativas significantes, o seu poder explicativo $\left(R^{2}\right)$ pode ser considerado baixo. Por exemplo, os resultados da Equação (1) apresentaram $R^{2}$ inferiores a 1\%. E o maior $\mathrm{R}^{2}$ é de $10,93 \%$ da Equação (2) que tem a NTGE como variável dependente. Mesmo com a consideração de fatores demográficos e acadêmicos, é possível que haja outros não considerados por este estudo que também explicam de forma relevante a variação do desempenho nas provas de componente específico e de formação geral e, consequentemente, do desempenho total dos estudantes no Enade 2018. Este ponto pode ser explorado por investigações futuras. 
Após as análises das Equações (1) e (2), a Tabela 6 mostra os resultados da Equação (3). O VIF médio de 1,71 sugere baixa multicolinearidade. Observa-se que após a inclusão da variável CURSO, os coeficientes tendem a aumentar, ao passo que a quantidade de livros lidos aumenta (1-2 livros: 0,299; 3-5 livros: 1,302; 6-8 livros: 1,161; +8 livros: 2,187), mantendo-se a lógica de relação positiva entre a leitura de livros extracurriculares e o desempenho discente.

Tabela 6

Resultados do modelo de regressão (3)

\begin{tabular}{lcccc}
\hline \multicolumn{1}{c}{ NTFG } & Coeficiente & EPR & t & p \\
\hline CONSTANTE & 48,342 & 0,237 & 204,370 & 0,000 \\
\hline LIVRO (1-2 livros) & 0,299 & 0,098 & 3,060 & 0,002 \\
\hline LIVRO (3-5 livros) & 1,302 & 0,103 & 12,670 & 0,000 \\
\hline LIVRO (6-8 livros) & 1,161 & 0,133 & 8,700 & 0,000 \\
\hline LIVRO (+8 livros) & 2,187 & 0,130 & 16,830 & 0,000 \\
\hline CURSO (ADM) & 1,528 & 0,088 & 17,300 & 0,000 \\
\hline CURSO (DIR) & 5,820 & 0,092 & 63,100 & 0,000 \\
\hline CURSO (ECO) & 7,222 & 0,205 & 35,200 & 0,000 \\
\hline CURSO (TUR) & 6,204 & 0,335 & 18,540 & 0,000 \\
\hline CURSO (SES) & 2,717 & 0,137 & 19,780 & 0,000 \\
\hline CURSO (ADP) & 8,544 & 0,322 & 26,520 & 0,000 \\
\hline CURSO (CS) & 9,439 & 0,191 & 49,470 & 0,000 \\
\hline CURSO (CSP) & 2,841 & 0,168 & 16,940 & 0,000 \\
\hline REFER & $-0,679$ & 0,026 & $-26,610$ & 0,000 \\
\hline OUTROS CONTROLES & Sim & Sim & Sim & Sim \\
\hline N & 337,072 & $\mathrm{~F}$ & $1,598,69$ & \\
\hline R2 & 0,0539 & Prob F & 0,00 & \\
\hline NOER & & & \\
\hline
\end{tabular}

Nota. EPR = Erro-padrão robusto. VIF médio $=1,71$.

Favor consultar o Apêndice II para observar a tabela completa.

No que concerne ao curso de graduação, constata-se que os estudantes de todos os cursos, com exceção dos de SES, obtiveram performances mais elevadas na prova de formação geral do que os estudantes de contabilidade (CON - categoria de referência). Como reportado na Tabela 4, os estudantes de contabilidade leem, proporcionalmente, menos do que os estudantes de outros cursos. Portanto, é esperado um desempenho menor. À exceção dos alunos de SES, os quais obtiveram, em média, 1,400 ponto a menos do que os de contabilidade, todos os outros obtiveram nota significativamente melhores. Nascimento et al. (2019) constatou que alunos de ciências contábeis tiveram dificuldades para compreender textos e Silva e Santos (2004) constataram que estudantes de Administração obtiveram o terceiro pior desempenho em compreensão de leitura dentre os oito cursos analisados. Por estas razões, propõe-se que alunos da área de ciências sociais aplicadas aprimorem as suas habilidades de leitura.

Portanto, os resultados encontrados a partir dos modelos de regressão sustentam que há relação positiva entre a leitura de livros extracurriculares e o desempenho acadêmico. Esta relação se mantém mesmo após a inserção de variáveis de controle. Apesar disso, a leitura em caráter extracurricular deve ser feita com razoabilidade, já que em excesso pode tornar-se prejudicial (Chen, 2007). Notadamente, mais pesquisas são necessárias em relação à percepção discente sobre a relevância das referências bibliográficas sugeridas pelos professores para a aprendizagem, visto que uma relação negativa foi identificada. Além disso, frisa-se que os modelos possuem poder explicativo baixo. Para a Equação (3), o $\mathrm{R}^{2}$ foi de 5,39\%. Desta forma, futuros estudos podem levar em conta outras variáveis importantes para explicar a performance acadêmica além daquelas consideradas nesta pesquisa, como, por exemplo, o conhecimento prévio (Miranda et al., 2015). 


\section{Considerações Finais}

Este estudo objetivou analisar a relação entre a leitura de livros extracurriculares e o desempenho acadêmico de estudantes da área de ciências sociais aplicadas. Desta forma, coletaram-se dados de 338.977 estudantes pertencentes a nove cursos de graduação que realizaram o Enade 2018. Para a análise dos dados, empregaram-se estatísticas descritivas, teste qui-quadrado e modelos de regressão múltipla.

Os resultados das estatísticas descritivas e do teste qui-quadrado indicaram que os cursos estão significativamente associados à quantidade de livros lidos. Ou seja, enquanto estudantes de determinados cursos (ex: CSJ) estão mais associados a maiores quantidades de livros lidos, outros estudantes pertencentes a outros cursos (ex: CON) estão mais relacionados a menores quantidades de livros lidos. Chama-se atenção especial para o curso de CON, cujos estudantes - de forma geral e proporcional aos outros cursos - estão lendo menos. Isso é preocupante porque, ainda que o seu poder explicativo $\left(\mathrm{R}^{2}\right)$ seja pequeno, os modelos de regressão produziram evidências de que há relação positiva entre a leitura de livros extracurriculares e a performance discente. Portanto, estudantes que leem mais tendem a obter melhores performances. Neste caso, alunos de CON podem querer ler mais. Adicionalmente, com exceção dos estudantes do curso de SES, foram encontradas evidências de que os estudantes de todos os cursos analisados performaram significativamente melhor do que os de CON na prova de formação geral do Enade 2018. Tomados em conjunto, estes resultados sugerem que a leitura de livros extracurriculares é relevante para a formação geral e específica do aluno, já que pode desenvolver habilidades de leitura, interpretação de texto e escrita.

Esta pesquisa possui duas principais implicações, as quais são discutidas na sequência. Primeiramente, os achados evidenciam que alguns cursos da área de ciências sociais aplicadas possuem estudantes menos propensos à prática de leitura de livros extracurriculares do que outros. De posse desses resultados, os coordenadores de curso podem tomar iniciativas que motivem mais a prática de leitura entre seus estudantes a fim de auxiliá-los em sua formação acadêmica, profissional e pessoal. Em segundo lugar, conforme os resultados de desempenho, verifica-se uma média reduzida especialmente na prova de formação geral $(38,7$ pontos de 100,0) por parte dos estudantes de ciências sociais aplicadas. Por esta razão, leituras que abarcam conteúdos além dos ministrados nos cursos de graduação são necessárias porque complementam a formação acadêmica dos universitários ao mesmo tempo em que adquirem conhecimentos gerais. Por conseguinte, as evidências deste estudo podem servir de alerta para estudantes que pretendem aumentar seu desempenho por meio da prática de leitura e motivação para que realizem mudanças em relação a hábitos de estudo e leituras extracurriculares.

Dentre as principais limitações da pesquisa, ressalta-se que a proxy de leitura de livros extracurriculares (LIVRO) é limitada, pois não abrange outras fontes de leitura, como jornais, revistas, revistas especializadas, artigos acadêmicos não relacionados ao curso de graduação etc. Além disso, a proxy é mensurada em categorias, limitando a quantidade de possíveis análises quantitativas. Estas limitações estão relacionadas à forma como a questão foi elaborada e aplicada pelo Enade, sobre as quais os pesquisadores não têm controle. Contudo, foram concentrados esforços no que foi possível fazer a partir desta proxy. Outra restrição é que a variável LIVRO captura a quantidade de livros lidos referente ao ano em que o estudante realiza a prova do Enade. Desta forma, é importante que análises longitudinais sobre leitura extracurricular, em particular de livros, sejam conduzidas para verificar a sua relação com a performance acadêmica ao longo do tempo.

Por fim, além das recomendações para pesquisas futuras já realizadas ao longo do artigo, indica-se a investigação dos fatores determinantes da leitura de livros extracurriculares de estudantes da área de ciências sociais aplicadas. O estudo de Levine et al. (2020) contribui nesse sentido. Todavia, como esta afirma, a literatura ainda é limitada. Tais resultados podem ser especialmente valiosos para coordenadores de curso, docentes e pais que tenham a intenção de encorajar mais a prática de leitura de seus estudantes e filhos. Complementarmente, considerando os resultados da variável REFER, sugere-se o estudo minucioso de como as leituras curriculares afetam o desempenho acadêmico, desejavelmente com medidas objetivas de leitura curricular e desempenho. Os resultados podem servir de subsídio para as decisões de coordenadores de curso e professores quanto à manutenção, atualização ou revisão das referências bibliográficas das disciplinas. 


\section{Referências}

Alhammad, R., \& Ku, H. (2019). Graduate students' perspectives on using e-books for academic learning, Educational Media International, 56(1), pp. 75-91. Doi: https://doi.org/10.1080/09523987.2019.1583460

Arana, A. R. de A., \& Klebis, A. B. S. O. (2015). A Importância do Incentivo à Leitura para o Processo de Formação do Aluno. XI Congresso Nacional De Educação - EDUCERE, pp. 26669-26686. Curitiba.

Araújo, E. A. T., Camargos, M. A. De, Camargos, M. C. S., \& Dias, A. T. (2013). Desempenho Acadêmico De Discentes Do Curso De Ciências Contábeis: Uma Análise Dos Seus Fatores Determinantes Em Uma Ies Privada. Contabilidade Vista \& Revista, 24(1), 60-83. Recuperado de http://revistas.face. ufmg.br/index.php/contabilidadevistaerevista/article/view/1181

Bartkus, K. R., Nemelka, B., Nemelka, M., \& Gardner, P. (2012). Clarifying The Meaning Of Extracurricular Activity: A Literature Review Of Definitions. American Journal of Business Education (AJBE), 5(6), 693. Doi: https://doi.org/10.19030/ajbe.v5i6.7391

Billor, N., Hadi, A. S., \& Velleman, P. F. (2000). BACON: blocked adaptive computationally efficient outlier nominators. Computational Statistics \& Data Analysis, 34(3), pp. 279-298. Doi: https://doi. org/10.1016/S0167-9473(99)00101-2

Cantalice, L. M. de, \& Oliveira, K. L. de. (2009). Estratégias de leitura e compreensão textual em universitários. Psicologia Escolar e Educacional, 13(2), pp. 227-234. Doi: https://doi.org/10.1590/ S1413-85572009000200004

Cardoso, R. L. (2006). Competências do contador: um estudo empírico. Tese de doutorado, Faculdade de Economia, Administração e Contabilidade, Universidade de São Paulo. Doi: https://doi. org/10.11606/T.12.2006.tde-03042007-100732

Chen, S.-Y. (2007). Extracurricular Reading Habits of College Students in Taiwan: Findings From Two National Surveys. Journal of Adolescent \& Adult Literacy, 50(8), pp. 642-653. Doi: https://doi. org/10.1598/JAAL.50.8.3

Conselho Nacional de Desenvolvimento Científico e Tecnológico (CNPq). (2019). Áreas do Conhecimento - Ciências Sociais Aplicadas. Recuperado de http://lattes.cnpq.br/web/dgp/ciencias-sociais-aplicadas

Corbucci, P. R. (2007). Texto para discussão no 1287 - Desafios da educação superior e desenvolvimento no Brasil. In IPEA Instituto de Pesquisa Economica Aplicada (Vol. 18). Recuperado de http://www. ipea.gov.br/portal/images/stories/PDFs/TDs/td_1287.pdf

Cunha, N. de B., \& Santos, A. A. A. dos. (2006). Relação entre a compreensão da leitura e a produção escrita em universitários. Psicologia: Reflexão e Crítica, 19(2), pp. 237-245. Doi: https://doi.org/10.1590/ S0102-79722006000200009

Fávero, L. P. (2015). Análise de dados: Modelos de regressão com Excel, STATA e SPSS. Rio de Janeiro: Elsevier.

Gallik, J. D. (1999). Do they read for pleasure? Recreational reading habits of college students. Journal of Adolescent \& Adult Literacy, 42(6), pp. 480-488. Recuperado de: http://www.jstor.org/ stable/40014062

Glewwe, P., Hanushek, E. A., Humpage, S., \& Ravina, R. (2015). School Resources and Educational Outcomes in Developing Countries: A Review of the Literature from 1990 to 2010. In Education Policy in Developing Countries, pp. 13-64. Doi: https://doi.org/10.7208/chicago/9780226078854.003.0002

Gordon, R. (2015). Regression Analysis for the Social Sciences. New York: Routledge. Doi://doi. org/10.4324/9781315748788 
Hussein, C. L. (1999). Treino e generalização de leitura crítica e criativa: um estudo experimental com universitários. Estudos de Psicologia (Campinas), 16(2), pp. 16-27. Doi: https://doi.org/10.1590/ S0103-166X1999000200002

Instituto Nacional de Estudos e Pesquisas Educacionais Anísio Teixeira (INEP). (2019). Microdados do Exame Nacional de Desempenho dos Estudantes. Recuperado de: https://www.gov.br/inep/pt-br/ acesso-a-informacao/dados-abertos/microdados/enade

Instituto Nacional de Estudos e Pesquisas Educacionais Anísio Teixeira (INEP). (2018). Edital No 40, de 19 de junho de 2018. Recuperado de: https://download.inep.gov.br/educacao_superior/enade/ edital/2018/edital_n40_de_19062018_enade_2018.pdf

Kirsch, I. S., \& Guthrie, J. T. (1984). Adult reading practices for work and leisure. Adult Education Quarterly, 34(4), pp. 213-232. Doi: https://doi.org/10.1177/0001848184034004003

Kuimova, M. V, \& Ukhov, S. A. (2016). Some Benefits of Extracurricular Reading in Foreign Language Teaching. PONTE, 72(4), pp. 276-280. Recuperado de http://earchive.tpu.ru/ bitstream/11683/37420/1/reprint-nw-13952.pdf

Levine, S. L., Cherrier, S., Holding, A. C., \& Koestner, R. (2020). For the love of reading: Recreational reading reduces psychological distress in college students and autonomous motivation is the key. Journal of American College Health, pp. 1-7. Doi: https://doi.org/10.1080/07448481.2020.1728280

Lieury, A., Lorant, S., Trosseille, B., Champault, F., \& Vourc'h, R. (2014). Video games vs. reading and school/cognitive performances: a study on 27000 middle school teenagers. Educational Psychology, 36(9), pp. 1560-1595. Doi:10.1080/01443410.2014.923556

Marini, A. (1986). Compreensão de Leitura no ensino superior: teste de um programa para treino de habilidades. Tese de doutorado, Instituto de Psicologia, Universidade de São Paulo.

McGaha, V., \& Fitzpatrick, J. (2010). Employment, Academic and Extracurricular Contributors to College Aspirations. Journal of College Admission, (207), pp. 22-29 Recuperado de https://acces.bibl.ulaval. $\mathrm{ca} /$ login?url=https://search.ebscohost.com/login.aspx?direct=true $\& \mathrm{db}=$ eue $\& A \mathrm{~N}=508156558 \&$ lan $\mathrm{g}=$ fr\&site $=$ ehost-live

Miranda, G. J., Lemos, K. C. da S., Oliveira, A. S. de, \& Ferreira, M. A. (2015). Determinantes do Desempenho Acadêmico na Área de Negócios. Revista Meta: Avaliação, 7(20), pp. 175-209. Doi: https://doi.org/10.22347/2175-2753v7i20.264

Mokhtari, K., Reichard, C. A., \& Gardner, A. (2009). The Impact of Internet and Television Use on the Reading Habits and Practices of College Students. Journal of Adolescent \& Adult Literacy, 52(7), pp. 609-619. Doi: https://doi.org/10.1598/JAAL.52.7.6

Mol, S. E., \& Bus, A. G. (2011). To read or not to read: A meta-analysis of print exposure from infancy to early adulthood. Psychological Bulletin, 137(2), pp. 267-296. Doi: https://doi.org/10.1037/a0021890

Nascimento, D. M. D. S., Garcia, E. A. D. R., \& Albuquerque Filho, A. R. (2019). Contribuição do hábito de leitura dos discentes do curso de Ciências Contábeis para o desenvolvimento de competências profissionais. Revista Catarinense Da Ciência Contábil, vol. 18(20), pp. 1-17. Doi: https://doi. org/10.16930/2237-766220192825

Nasu, V. H. (2018). A importância da leitura extracurricular na educação superior: reflexos no desempenho acadêmico e no tempo de estudo de estudantes de ciências contábeis. Advances in Scientific and Applied Accounting, 11(3), pp. 484-501. Doi: https://doi.org/10.14392/ASAA.2018110307

Oliveira, D. J. de A., \& Caggy, R. C. S. S. (2013). Análise dos fatores influenciadores do desempenho acadêmico de estudantes de administração: um olhar do docente. Revista Formadores: Vivências e Estudos, 6(1), pp. 5-28. Recuperado de http://www.seer-adventista.com.br/ojs/index.php/ formadores/article/view/285/395 
Oliveira, K. L. de, \& Santos, A. A. A. dos. (2006). Compreensão de textos e desempenho acadêmico. Revista de Psicologia Da Vetor Editora, 7(1), 19-27. Recuperado de http://pepsic.bvsalud.org/scielo. php?script=sci_arttext\&pid=S1676-73142006000100004

Oliveira, K. L. de, \& Santos, A. A. A. Dos. (2005). Compreensão em leitura e avaliação da aprendizagem em universitários. Psicologia: Reflexão e Crítica, 18(1), pp. 118-124. Doi: https://doi.org/10.1590/ S0102-79722005000100016

Oliveira, K. L. de, Santos, A. A. A. dos, \& Primi, R. (2003). Estudo das relações entre compreensão em leitura e desempenho acadêmico na universidade. Interação Em Psicologia, 7(1), pp. 19-25. Doi: https://doi.org/10.5380/psi.v7i1.3203

Rubin, R. S., Bommer, W. H., \& Baldwin, T. T. (2002). Using extracurricular activity as an indicator of interpersonal skill: Prudent evaluation or recruiting malpractice? Human Resource Management, 41(4), pp. 441-454. Doi: https://doi.org/10.1002/hrm.10053

Rynes, S. L., Trank, C. Q., Lawson, A. M., \& Ilies, R. (2003). Behavioral Coursework in Business Education: Growing Evidence of a Legitimacy Crisis. Academy of Management Learning \& Education, 2(3), pp. 269-283. Doi: https://doi.org/10.5465/amle.2003.10932135

Sampaio, I. S., \& Santos, A. A. A. dos. (2002). Leitura e redação entre universitários: avaliação de um programa de intervenção. Psicologia Em Estudo, 7(1), pp. 31-38. Doi: https://doi.org/10.1590/S141373722002000100006

Santos, A. A. A. dos, Suehiro, A. C. B., \& Oliveira, K. L. de. (2004). Habilidades em compreensão da leitura: um estudo com estudantes de psicologia. Estudos de Psicologia (Campinas), 21(2), pp. 29-41. Doi: https://doi.org/10.1590/S0103-166X2004000200003

Sauerwein, M., Theis, D., \& Fischer, N. (2016). How Youths' Profiles of Extracurricular and Leisure Activity Affect Their Social Development and Academic Achievement. International Journal for Research on Extended Education, 4(1), pp. 103-124. Doi: https://doi.org/10.3224/ijree.v4i1.24778

Silva, M. J. M. da, \& Santos, A. A. A. dos. (2004). A avaliação da compreensão em leitura e o desempenho acadêmico de universitários. Psicologia Em Estudo, 9(3), pp. 459-467. Recuperado de http://www. scielo.br/scielo.php?script=sci_arttext\&pid=S0103-863X2008000300009\&lng=pt\&nrm=iso\&tlng=pt

Takala, T., Kallo, J., Kauko, J., \& Rinne, R. (2018). One Size for All? Policy Advice of the World Bank and the OECD on Quality Assurance and Evaluation of School Education in Russia, Brazil, and China. Wiseman, A.W. \& Davidson, P.M. (Ed.) Cross-nationally Comparative, Evidence-based Educational Policymaking and Reform (International Perspectives on Education and Society, Vol. 35), Emerald Publishing Limited, pp. 301-319. Doi: https://doi.org/10.1108/S1479-367920180000035009

Tourinho, C. (2011). Refletindo sobre a Dificuldade de Leitura em Estudantes do Ensino Superior: "Deficiência" ou Simples Falta de Hábito? Revista Lugares de Educação, 1(2), pp. 325-346. Doi: https://doi.org/10.18788/2237-1451/rle.v1n2p325-346

University Ranking by Academic Performance. (2020). URAP is a non-profit organization which was established at the Informatics Institute of Middle East Technical University in 2009. Recuperado de https://www.urapcenter.org/

Weber, S. (2010). Bacon: An Effective way to Detect Outliers in Multivariate Data Using Stata (and Mata). The Stata Journal: Promoting Communications on Statistics and Stata, 10(3), pp. 331-338. Doi: https://doi.org/10.1177/1536867X1001000302

Yan, X., \& Su, X. (2013). Linear regression analysis: theory and computing. Toh Tuck: World Scientific Publishing Co. Pte. Ltd. 


\section{Apêndice I}

Tabela completa

Resultados dos modelos de regressão (1) e (2)

\begin{tabular}{|c|c|c|c|c|c|c|}
\hline \multirow{2}{*}{$\begin{array}{l}\text { VAR. DEP. } \\
\text { EQUAÇÃO }\end{array}$} & \multicolumn{2}{|c|}{ NTFG } & \multicolumn{2}{|c|}{ NTCE } & \multicolumn{2}{|c|}{ NTGE } \\
\hline & (1) & (2) & (1) & (2) & (1) & (2) \\
\hline & $\begin{array}{l}\text { Coeficiente } \\
\text { (EPR) }\end{array}$ & $\begin{array}{l}\text { Coeficiente } \\
\text { (EPR) }\end{array}$ & $\begin{array}{l}\text { Coeficiente } \\
\text { (EPR) }\end{array}$ & $\begin{array}{l}\text { Coeficiente } \\
\text { (EPR) }\end{array}$ & $\begin{array}{l}\text { Coeficiente } \\
\text { (EPR) }\end{array}$ & $\begin{array}{l}\text { Coeficiente } \\
\text { (EPR) }\end{array}$ \\
\hline \multirow{2}{*}{ CONSTANTE } & 44,763 & 49,707 & 37,802 & 41,042 & 39,555 & 43,221 \\
\hline & $(0,080)$ & $(0,225)$ & $(0,069)$ & $(0,197)$ & $(0,064)$ & $(0,181)$ \\
\hline \multirow{2}{*}{$\begin{array}{c}\text { LIVRO } \\
\text { (1-2 livros) }\end{array}$} & $0,161 *$ & $0,572 * \star \star$ & $-0,047$ & $-0,198$ & 0,005 & $-0,006$ \\
\hline & $(0,094)$ & $(0,099)$ & $(0,082)$ & $(0,086)$ & $(0,076)$ & $(0,078)$ \\
\hline \multirow{2}{*}{$\begin{array}{l}\text { LIVRO } \\
\text { (3-5 livros) }\end{array}$} & $2,114 * \star \star$ & $1,978 * * *$ & $1,360 * * *$ & $0,637 * \star *$ & $1,548 * * *$ & $0,972 * \star \star$ \\
\hline & $(0,098)$ & $(0,104)$ & $(0,085)$ & $(0,090)$ & $(0,078)$ & $(0,083)$ \\
\hline \multirow{2}{*}{$\begin{array}{l}\text { LIVRO } \\
\text { (6-8 livros) }\end{array}$} & $2,484 * * *$ & $1,968 * * *$ & $1,748 * * *$ & $0,614^{* * *}$ & $1,932 * * *$ & $0,953 * * *$ \\
\hline & $(0,131)$ & $(0,134)$ & $(0,115)$ & $(0,118)$ & $(0,107)$ & $(0,108)$ \\
\hline \multirow{2}{*}{$\begin{array}{c}\text { LIVRO } \\
\text { (+8 livros) }\end{array}$} & $4,403 * * \star$ & $3,115^{\star \star *}$ & $3,291 * * *$ & $1,431 * * *$ & $3,569 * * *$ & $1,852 * * *$ \\
\hline & $(0,125)$ & $(0,131)$ & $(0,109)$ & $(0,115)$ & $(0,102)$ & $(0,106)$ \\
\hline \multirow{2}{*}{ REFER } & & $-0,731 * * *$ & & $-0,294 * * *$ & & $-0,403 * * *$ \\
\hline & & $(0,026)$ & & $(0,022)$ & & $(0,021)$ \\
\hline \multirow{2}{*}{ MODAL } & & $4,960 * \star *$ & & $5,206 * * *$ & & $5,145^{* * *}$ \\
\hline & & $(0,092)$ & & $(0,079)$ & & $(0,072)$ \\
\hline \multirow{2}{*}{ REGIAO (N) } & & $-0,909 * * *$ & & $-2,472 * * *$ & & $-2,081 * * *$ \\
\hline & & $(0,134)$ & & $(0,115)$ & & $(0,106)$ \\
\hline \multirow{2}{*}{ REGIAO (NE) } & & $-0,174^{\star *}$ & & $-0,903 * *$ & & $-0,721$ ** \\
\hline & & $(0,084)$ & & $(0,074)$ & & $(0,068)$ \\
\hline \multirow{2}{*}{ REGIAO (S) } & & $-0,328 * * \star$ & & $-0,696 * * *$ & & $-0,606 * \star \star$ \\
\hline & & $(0,080)$ & & $(0,070)$ & & $(0,065)$ \\
\hline \multirow{2}{*}{ REGIAO (CO) } & & $-1,593 * * \star$ & & $-2,121 * * \star$ & & $-1,999 * * \star$ \\
\hline & & $(0,109)$ & & $(0,095)$ & & $(0,087)$ \\
\hline \multirow{2}{*}{ TURNO (Matutino) } & & $-2,123^{* * *}$ & & $-2,139 * * \star$ & & $-2,136 * \star \star$ \\
\hline & & $(0,141)$ & & $(0,128)$ & & $(0,117)$ \\
\hline \multirow{2}{*}{ TURNO (Vespertino) } & & $-2,680 * * *$ & & $-1,742 * * *$ & & $-1,977 * * *$ \\
\hline & & $(0,210)$ & & $(0,194)$ & & $(0,177)$ \\
\hline \multirow{2}{*}{ TURNO (Noturno) } & & $-2,624 * * *$ & & $-4,957 * * \star$ & & $-5,279 * * \star$ \\
\hline & & $(0,125)$ & & $(0,114)$ & & $(0,104)$ \\
\hline \multirow{2}{*}{ IDADE } & & $-0,180 * \star \star$ & & $-0,166^{* \star *}$ & & $-0,169 * * *$ \\
\hline & & $(0,004)$ & & $(0,004)$ & & $(0,003)$ \\
\hline \multirow{2}{*}{ SEXO } & & $3,265^{* * *}$ & & $1,140 * * *$ & & $1,671 * * *$ \\
\hline & & $(0,061)$ & & $(0,054)$ & & $(0,049)$ \\
\hline \multirow{2}{*}{ ECIVIL (Casado) } & & $-0,186^{* \star}$ & & $-0,078$ & & $-0,105$ \\
\hline & & $(0,082)$ & & $(0,071)$ & & $(0,065)$ \\
\hline \multirow{2}{*}{ ECIVIL (Divorciado) } & & 0,045 & & $-0,333^{* \star}$ & & $-0,239 *$ \\
\hline & & $(0,174)$ & & $(0,147)$ & & $(0,135)$ \\
\hline \multirow{2}{*}{ ECIVIL (Viúvo) } & & $-1,601 * * *$ & & $-0,634$ & & $-0,877 * *$ \\
\hline & & $(0,511)$ & & $(0,450)$ & & $(0,411)$ \\
\hline
\end{tabular}




\begin{tabular}{|c|c|c|c|c|c|c|}
\hline \multirow{2}{*}{$\begin{array}{l}\text { VAR. DEP. } \\
\text { EQUAÇÃO }\end{array}$} & \multicolumn{2}{|c|}{ NTFG } & \multicolumn{2}{|c|}{ NTCE } & \multicolumn{2}{|c|}{ NTGE } \\
\hline & (1) & (2) & (1) & (2) & (1) & (2) \\
\hline & $\begin{array}{l}\text { Coeficiente } \\
\text { (EPR) }\end{array}$ & $\begin{array}{l}\text { Coeficiente } \\
\text { (EPR) }\end{array}$ & $\begin{array}{l}\text { Coeficiente } \\
\text { (EPR) }\end{array}$ & $\begin{array}{l}\text { Coeficiente } \\
\text { (EPR) }\end{array}$ & $\begin{array}{l}\text { Coeficiente } \\
\text { (EPR) }\end{array}$ & $\begin{array}{l}\text { Coeficiente } \\
\text { (EPR) }\end{array}$ \\
\hline \multirow{2}{*}{ ECIVIL (Outro) } & & $0,828 * * *$ & & $0,500 * * *$ & & $0,582^{* * *}$ \\
\hline & & $(0,164)$ & & $(0,140)$ & & $(0,129)$ \\
\hline \multirow{2}{*}{ ETNIA (Negra) } & & $-0,804 * \star \star$ & & $-0,382 * \star *$ & & $-0,488 * \star \star$ \\
\hline & & $(0,107)$ & & $(0,095)$ & & $(0,086)$ \\
\hline \multirow{2}{*}{ ETNIA (Amarela) } & & $-2,539 * * *$ & & $-1,739 * * *$ & & $-1,940 * * *$ \\
\hline & & $(0,191)$ & & $(0,167)$ & & $(0,152)$ \\
\hline \multirow{2}{*}{ ETNIA (Parda) } & & $-1,301 * * *$ & & $-0,975^{* * *}$ & & $-1,056 * * *$ \\
\hline & & $(0,068)$ & & $(0,060)$ & & $(0,055)$ \\
\hline \multirow{2}{*}{ ETNIA (Indígena) } & & $-3,552 * \star *$ & & $-2,050 * \star \star$ & & $-2,425^{\star \star \star}$ \\
\hline & & $(0,164)$ & & $(0,480)$ & & $(0,444)$ \\
\hline \multirow{2}{*}{$\begin{array}{l}\text { RENDA } \\
\text { (3-6 SM) }\end{array}$} & & $2,621 * * *$ & & $1,825 * * *$ & & $2,024 * * *$ \\
\hline & & $(0,067)$ & & $(0,059)$ & & $(0,054)$ \\
\hline \multirow{2}{*}{$\begin{array}{l}\text { RENDA } \\
(6+5 M)\end{array}$} & & $7,360 * * *$ & & $4,747 * * *$ & & $5,400 * * *$ \\
\hline & & $(0,084)$ & & $(0,074)$ & & $(0,069)$ \\
\hline \multirow{2}{*}{$\begin{array}{l}\text { HOEST } \\
(1-3 \mathrm{H})\end{array}$} & & $0,773 * * *$ & & $1,021 * * *$ & & $0,958 * * *$ \\
\hline & & $(0,124)$ & & $(0,107)$ & & $(0,098)$ \\
\hline \multirow{2}{*}{$\begin{array}{l}\text { HOEST } \\
(4-7 \mathrm{H})\end{array}$} & & $2,917^{* \star *}$ & & $3,163^{* * *}$ & & $3,101 * * *$ \\
\hline & & $(0,132)$ & & $(0,114)$ & & $(0,105)$ \\
\hline \multirow{2}{*}{$\begin{array}{l}\text { HOEST } \\
(8-12 \mathrm{H})\end{array}$} & & $4,356 * * \star$ & & $4,616 * \star \star$ & & $4,550 * * *$ \\
\hline & & $(0,155)$ & & $(0,136)$ & & $(0,125)$ \\
\hline \multirow{2}{*}{ HOEST $(12+\mathrm{H})$} & & $4,493 * \star \star$ & & $5,493 * * *$ & & $5,243 * * *$ \\
\hline & & $(0,168)$ & & $(0,148)$ & & $(0,180)$ \\
\hline $\mathrm{N}$ & 337,072 & 326,500 & 337,072 & 326,500 & 337,072 & 326,500 \\
\hline $\mathrm{F} /$ prob $>\mathrm{F}$ & $546,89 / 0,00$ & $\begin{array}{c}1335,78 / \\
0,00\end{array}$ & $407,50 / 0,00$ & $\begin{array}{c}1054,44 / \\
0,00\end{array}$ & $548,64 / 0,00$ & $1409,74 / 0,00$ \\
\hline $\mathrm{R} 2$ & 0,0067 & 0,1042 & 0,0051 & 0,0835 & 0,0068 & 0,1093 \\
\hline VIF médio & 1,86 & 1,74 & 1,86 & 1,74 & 1,86 & 1,74 \\
\hline
\end{tabular}

Nota. VAR. DEP. = variável dependente. EPR = Erro-padrão robusto. Estão entre parênteses. VIF médio

(A)Também foram estimadas via MQO com erros-padrão tradicionais (não-robustos). Os resultados foram muito semelhantes aos apresentados nesta tabela. Ademais, variáveis de nível educacional do pai e da mãe também foram coletadas e inseridas nos modelos. Os principais resultados (relacionados à variável LIVRO) foram muito similares. (B)Os modelos de regressão possuem menos observações do que a amostra inteira devido aos missing values das variáveis. ***, ** e * representam o nível de significância a 1\%,5\% e 10\%, respectivamente. 


\section{Apêndice II}

Tabela completa

Resultados do modelo de regressão (3)

\begin{tabular}{|c|c|c|c|c|}
\hline NTFG & Coeficiente & EPR & $\mathbf{t}$ & $\mathbf{p}$ \\
\hline CONSTANTE & 48,342 & 0,237 & 204,370 & 0,000 \\
\hline LIVRO (1-2 livros) & 0,299 & 0,098 & 3,060 & 0,002 \\
\hline LIVRO (3-5 livros) & 1,302 & 0,103 & 12,670 & 0,000 \\
\hline LIVRO (6-8 livros) & 1,161 & 0,133 & 8,700 & 0,000 \\
\hline LIVRO (+8 livros) & 2,187 & 0,130 & 16,830 & 0,000 \\
\hline CURSO (ADM) & 1,528 & 0,088 & 17,300 & 0,000 \\
\hline CURSO (DIR) & 5,820 & 0,092 & 63,100 & 0,000 \\
\hline CURSO (ECO) & 7,222 & 0,205 & 35,200 & 0,000 \\
\hline CURSO (TUR) & 6,204 & 0,335 & 18,540 & 0,000 \\
\hline CURSO (SES) & 2,717 & 0,137 & 19,780 & 0,000 \\
\hline CURSO (ADP) & 8,544 & 0,322 & 26,520 & 0,000 \\
\hline CURSO (CSJ) & 9,439 & 0,191 & 49,470 & 0,000 \\
\hline CURSO (CSP) & 2,841 & 0,168 & 16,940 & 0,000 \\
\hline REFER & $-0,679$ & 0,026 & $-26,610$ & 0,000 \\
\hline MODAL & 2,885 & 0,099 & 29,230 & 0,000 \\
\hline REGIAO (N) & $-1,055$ & 0,133 & $-7,950$ & 0,000 \\
\hline REGIAO (NE) & $-0,201$ & 0,083 & $-2,430$ & 0,015 \\
\hline REGIAO (S) & $-0,265$ & 0,080 & $-3,330$ & 0,001 \\
\hline REGIAO (CO) & $-1,878$ & 0,109 & $-17,260$ & 0,000 \\
\hline TURNO (Matutino) & $-2,360$ & 0,144 & $-16,360$ & 0,000 \\
\hline TURNO (Vespertino) & $-3,073$ & 0,212 & $-14,510$ & 0,000 \\
\hline TURNO (Noturno) & $-5,227$ & 0,128 & $-40,830$ & 0,000 \\
\hline IDADE & $-0,209$ & 0,004 & $-47,100$ & 0,000 \\
\hline SEXO & 3,271 & 0,062 & 53,090 & 0,000 \\
\hline ECIVIL (Casado) & 0,045 & 0,081 & 0,550 & 0,583 \\
\hline ECIVIL (Divorciado) & 0,024 & 0,173 & 0,140 & 0,888 \\
\hline ECIVIL (Viúvo) & $-1,568$ & 0,513 & $-3,060$ & 0,002 \\
\hline ECIVIL (Outro) & 0,870 & 0,162 & 5,360 & 0,000 \\
\hline ETNIA (Negra) & $-0,750$ & 0,106 & $-7,080$ & 0,000 \\
\hline ETNIA (Amarela) & $-2,259$ & 0,189 & $-11,920$ & 0,000 \\
\hline ETNIA (Parda) & $-1,136$ & 0,068 & $-16,770$ & 0,000 \\
\hline ETNIA (Indígena) & $-3,473$ & 0,555 & $-6,260$ & 0,000 \\
\hline RENDA (3-6 SM) & 2,683 & 0,067 & 40,180 & 0,000 \\
\hline RENDA (6+ SM) & 7,090 & 0,084 & 84,880 & 0,000 \\
\hline HOEST $(1-3 \mathrm{H})$ & 0,821 & 0,123 & 6,690 & 0,000 \\
\hline HOEST (4-7H) & 2,802 & 0,131 & 21,470 & 0,000 \\
\hline HOEST $(8-12 \mathrm{H})$ & 4,101 & 0,154 & 26,700 & 0,000 \\
\hline HOEST $(12+\mathrm{H})$ & 4,158 & 0,165 & 25,130 & 0,000 \\
\hline $\mathrm{N}$ & 337,072 & $\mathrm{~F}$ & $1,598,69$ & \\
\hline R2 & 0.0539 & Prob F & 0,00 & \\
\hline
\end{tabular}

Nota. EPR $=$ Erro-padrão robusto. VIF médio $=1,71$. 